COMUNICAÇÃOCIENTÍFICA

\title{
PÓS-COLHEITA DE MAMÃO HÍBRIDO UENF/CALIMAN O1 CULTIVADO NO RIO GRANDE DO NORTE ${ }^{1}$
}

\author{
PATRÍCIA LÍGIA DANTAS DE MORAIS² , GEOMAR GALDINO DA SILVA ${ }^{3}$, JOSIVAN BARBOSA MENEZES ${ }^{4}$, \\ FRANCISCO EMANUEL NOGUEIRA MAIA ${ }^{5}$, DJANGO JESUS DANTAS ${ }^{6}$, RUI SALES JÚNIOR ${ }^{7}$
}

RESUMO - No Brasil, foi desenvolvido um novo híbrido de mamão obtido através de melhoramento do cruzamento entre um progenitor do Grupo Formosa e um progenitor do Grupo Solo. Recentemente, os produtores de mamões do Rio Grande do Norte introduziram o cultivo desse híbrido em seus pomares: no entanto, os estudos acerca do potencial de conservação desses frutos restringem-se aos testes realizados nas próprias empresas. O presente trabalho propôs-se a avaliar a vida útil pós-colheita do mamão híbrido UENF/ Caliman 01 cultivado no Estado do Rio Grande do Norte. Os frutos foram provenientes de um plantio comercial, localizado no município de Ceará-Mirim-RN. Os mamões foram colhidos no estádio de maturação I (menos de 15\% da superfície da casca amarela). No galpão de embalagem, os frutos passaram por lavagem, seleção, tratamentos hidrotérmico, imersão em fungicida e cera. No laboratório da Universidade Federal Rural do Semi-Árido (Mossoró-RN), os frutos foram armazenados à temperatura de $25^{\circ} \mathrm{C} \pm 2^{\circ} \mathrm{C}$ e umidade relativa de $55 \% \pm 5 \%$. Aos $0 ; 2 ; 4 ; 6 ; 8$ e 10 dias de armazenamento, realizaram-se avaliações sobre as seguintes variáveis: aparência externa e interna, coloração da casca, perda de massa, firmeza, sólidos solúveis, acidez titulável, pH e açúcares. Esse híbrido apresenta características fenotípicas do Grupo Formosa, com frutos alongados, massa média de 1,28 kg, polpa com espessura de 2,74 cm, coloração vermelha e conteúdo elevado de sólidos solúveis $(13,65 \%)$ e açúcares (10,53\%). As variáveis de qualidade analisadas limitaram a vida útil póscolheita do híbrido UENF/Caliman 01 em oito dias.

Termos para indexaçã̃: Carica papaya L., conservação, qualidade, cultivar.

\section{POSTHARVEST SHELF LIFE OF PAPAYA UENF/CALIMAN 01 PRODUCED IN RIO GRANDE DO NORTE}

\begin{abstract}
A new papaya hybrid was developed in Brazil obtained by breeding with the crossing of progenitors from Solo $\mathrm{x}$ Formosa groups. Recently, in the state of Rio Grande do Norte, Brazil, this hybrid was introduced by the farmers in their orchards. However, the studies concerning to the conservation potential of these fruits was limited to the tests accomplished in commercial farms. This work purpose was to evaluate the hybrid UENF/Caliman shelf life produced in the state of Rio Grande Norte. Fruit were harvested at physiological maturity, packaged and transported to the Semi-arid Federal Rural University laboratory, in Mossoró City, state of Rio Grande do Norte. Fruits were stored at $25{ }^{\circ} \mathrm{C}( \pm 2)$ and $55 \%( \pm 5)$ of relative humidity for $0,2,4,6,8$ and 10 days. The experiment was completely randomized with 6 treatments. Were evaluated the variables: mass loss, external appearance, firmness, pulp color, titratable acidity, $\mathrm{pH}$, soluble solids and total soluble sugars. The hybrid presents phenotypic characteristics of the 'Formosa' papaya group, with elongated fruits, $1,28 \mathrm{~kg}$ of medium mass, $2,74 \mathrm{~cm}$ of pulp thickness, red coloration of the pulp, high content of soluble solids $(13,65 \%)$ and sugars $(10,53 \%)$. The quality variables analyzed limited at postharvest shelf life of the hybrid UENF/ Caliman 01 to eight days.

Index terms: Carica papaya L., conservation, quality, hybrid.
\end{abstract}

'(Trabalho 022-07). Recebido em: 18-01-2007. Aceito para publicação em: 10-08-2007.

${ }^{2}$ Dra. Sc., em Fisiologia Vegetal. Universidade Federal Rural do Semi-Árido - UFERSA. Mossoró-RN, CP 137. E-mail: plmorais@hotmail.com.

${ }^{3}$ Dr. em Agronomia. Universidade Federal Rural do Semi-Árido - UFERSA. E-mail: geomargaldino@yahoo.com.br.

${ }^{4}$ Dr. em Ciências dos Alimentos. Universidade Federal Rural do Semi-Árido - UFERSA. E-mail: reitor@ufersa.edu.br

${ }^{5}$ Bolsista de Iniciação Científica. Universidade Federal Rural do Semi-Árido - UFERSA. E-mail: maiafen@yahoo.com.br

${ }^{6}$ Aluno de Mestrado - Universidade Federal Rural do Semi-Árido - UFERSA. E-mail: djdagn@yahoo.com.br

${ }^{7}$ Dr. em Fitopatologia. Universidade Federal Rural do Semi-Árido - UFERSA. E-mail: ruisales@ufersa.edu.br. 
O mamão (Carica papaya L.) originário da América tropical adaptou-se muito bem ao Brasil, que se tornou o maior produtor mundial e o terceiro exportador desse fruto. Os Estados da Bahia e do Espírito Santo concentram mais de 70\% da área cultivada e da produção do País. Recentemente, algumas empresas produtoras de mamão instalaram-se no Rio Grande do Norte, expandindo sua produção no Estado, sendo os municípios de São José de Mipibu, Monte Alegre, Ceará Mirim, Nísia Floresta, Baraúna e Baixo Assu os principais municípios produtores (Assessoria de Comunicação Social do RN, 2006).

Dos problemas relacionados com a cultura do mamão, ressalta-se a limitação de alternativas quanto à escolha de cultivares e/ou híbridos comerciais para o plantio que atendam tanto às exigências do mercado nacional como do internacional. Aliado a isto, o elevado preço das sementes híbridas dos mamoeiros do grupo Formosa tem levado muitos fruticultores a utilizar plantios sucessivos com as gerações $\mathrm{F}_{2}, \mathrm{~F}_{3}$ e $\mathrm{F}_{4}$, acarretando inúmeros problemas, sobretudo com a perda de vigor e segregação para o formato do fruto (Marin et al., 2001).

No Brasil, foi desenvolvido um novo híbrido de mamão obtido do cruzamento entre um progenitor do Grupo Formosa e um progenitor do Grupo Solo. Recentemente, os produtores de mamões do Rio Grande do Norte introduziram o cultivo desse híbrido em seus pomares; no entanto, os estudos acerca do potencial de conservação desses frutos produzidos nesse Estado restringem-se aos testes realizados nas próprias empresas. $\mathrm{O}$ presente trabalho propôs-se a avaliar a vida útil pós-colheita do mamão híbrido UENF/Caliman 01, cultivado no Estado do Rio Grande do Norte.

Foram colhidos frutos de mamoeiro do híbrido UENF/ Caliman-01 produzidos em pomar comercial da Empresa Caliman Agrícola, localizada no município de Pureza, no Estado do Rio Grande do Norte. Os mamões foram colhidos no estádio de maturação I (menos de 15\% da superfície da casca amarela e o restante com coloração verde-clara). $\mathrm{Na}$ ocasião, foram selecionados frutos sem defeitos aparentes e livres de doenças que, em seguida, foram transportados em caixas de plástico forradas com plástico bolha, para o galpão de embalagem, da empresa. No galpão de embalagem, os frutos foram lavados com água, tratados hidrotermicamente $\left(48^{\circ} \mathrm{C}\right.$ por 20 minutos), resfriados com água fria $\left(10^{\circ} \mathrm{C}\right.$ por 10 minutos $)$, imersos por um minuto em solução do fungicida Sportak ${ }^{\circledR}$ e, em seguida, tratados com outro fungicida Tecto, à concentração de $100 \mathrm{~mL} / 100 \mathrm{~L}$ de calda de cera de carnaúba a $25 \%$.

No laboratório de Agricultura Irrigada na Universidade Federal Rural do Semi-Árido, uma amostragem de 48 frutos foi caracterizada por ocasião da colheita quanto à espessura da polpa, comprimentos longitudinal e transversal do fruto e massa do fruto. Em seguida, o experimento foi instalado em delineamento inteiramente casualizado, onde os tratamentos foram os tempos de armazenamento, ou seja, $0 ; 2 ; 4 ; 6 ; 8$ e 10 dias, com quatro repetições compostas de dois frutos por parcela. Os frutos foram mantidos por 10 dias a $25^{\circ} \mathrm{C} \pm 2^{\circ} \mathrm{C}$ e umidade relativa de $55 \% \pm$ $5 \%$, com avaliações a cada dois dias.

Para a determinação da massa fresca, utilizou-se balança semi-analítica. E a perda de massa fresca foi obtida tomando-se como referência a massa inicial e final do fruto, em cada intervalo de análise. Os comprimentos dos frutos, a espessura da polpa e os diâmetros da cavidade interna foram medidos com o auxílio de um paquímetro. A firmeza da polpa foi determinada com a utilização de um penetrômetro tipo Fruit Pressure Tester TR, com ponteira de $8 \mathrm{~mm}$ de diâmetro. No dia da colheita, os frutos apresentavamse bastante firmes, não sendo possível detectar leitura com o penetrômetro utilizado. A evolução da coloração da casca foi determinada por meio de escala subjetiva de notas ( 1 a 6 ), adaptada da FrutiSéries (2000), onde: nota $1=$ fruto que estava completamente com a cor da casca verde; nota $2=$ apenas $15 \%$ da superfície amarela; nota $3=$ apresentavam $25 \%$ da cor amarela; nota $4=50 \%$ da cor amarela; nota $5=.51$ a $75 \%$ da cor amarela; nota $6=76$ a $100 \%$ da cor amarela. Determinou-se também a aparência externa e interna com a utilização de escala subjetiva de nota segundo Rocha et al. (2005), sendo: nota $1=$ extremamente deteriorado; nota $2=$ severamente deteriorado; 3 = média deterioração; 4 = leve deterioração, e 5 = ausência de deterioração. Os frutos com notas iguais ou inferiores a 3 foram considerados impróprios para o consumo. Para a aparência externa, levou-se em consideração: a presença de depressões, fungos e murchamento. No caso da aparência interna, observaram-se amolecimento interno da polpa, sementes soltas e presença de doenças. O conteúdo de sólidos solúveis (SS) foi determinado com o auxílio de um refratômetro digital, modelo PR-100 Pallete da marca ATAGO, de acordo com o indicado pela Association of Official Analytical Chemists (2002). A acidez titulável (AT) foi determinada conforme metodologia do Instituto Adolfo Lutz (1985). Os açúcares solúveis totais, conforme Yemn \& Wills (1954).

$\mathrm{Na}$ caracterização realizada nos frutos utilizados no presente trabalho, observou que o híbrido UENF/Caliman 01 apresenta características fenotípicas do Grupo Formosa, com frutos alongados (comprimento longitudinal de $21,03 \mathrm{~cm} \mathrm{e}$ transversal de $10,96 \mathrm{~cm}$ ), peso médio de $1,28 \mathrm{~kg}$ e espessura da polpa de $2,74 \mathrm{~cm}$

A perda de massa fresca aumentou de forma linear com o tempo de armazenamento. Observou-se, no oitavo dia, que os frutos haviam perdido 10,74\% da massa inicial (Figura 1A). Embora esse valor de perda de massa seja considerado crítico para o mamão, não foi constatado nenhum sintoma de enrugamento aparente que comprometesse a aparência dos frutos. Somente depois do oitavo dia, foram observados sinais visíveis de enrugamento, comprometendo a aparência dos frutos e tornandoos inaptos para comercialização. No final do armazenamento, aos 10 dias, os frutos atingiram uma perda de massa em torno de 13,4 $\%$, semelhante ao observado por An \& Paul (1990). Essa alta desidratação dos frutos, provavelmente, ocorreu devido à baixa umidade relativa $(55 \pm 5)$ do ambiente de armazenamento.

A firmeza da polpa decresceu linearmente com o tempo de armazenamento (Figura 1B). Observou-se uma redução de 25,50 $\mathrm{N}$ para $13,45 \mathrm{~N}$ do segundo ao oitavo dia de armazenamento, respectivamente. Essa firmeza constatada no presente trabalho foi inferior à encontrada por Pereira et al. (2006) para a cultivar mamão Formosa 'Tainung 1', que obteve uma firmeza um pouco inferior a $30 \mathrm{~N}$ aos oito dias de armazenamento $\left(27^{\circ} \mathrm{C} \mathrm{e} 70 \% \mathrm{UR}\right)$, e no dia da colheita a firmeza ficou em torno de $133 \mathrm{~N}$. Um dos 
principais atributos de qualidade que, freqüentemente, estabelece a vida útil pós-colheita do mamão, é a firmeza. A velocidade de amaciamento depois de colhido é mais ou menos rápida, dependendo da consistência inicial e da tecnologia de conservação empregada. Este processo é irreversível e está estritamente ligado ao seu estado de maturação.

Houve rápido avanço da coloração amarela dos frutos ao longo do armazenamento, e, no quarto dia, todos os frutos se encontravam com a casca totalmente amarela (Figura 2A). Observou-se que o mamão UENF/Caliman 01 amadureceu rapidamente nessa temperatura. Segundo Oliveira et al. (2002), a mudança de cor da casca é uma das variáveis físicas mais utilizadas para avaliar os estádios de maturação de frutas.

Houve um pequeno acréscimo nos teores de sólidos solúveis e açúcares solúveis totais ao longo do armazenamento, entretanto não foi estatisticamente significativo. Os valores médios obtidos foram $13,65^{\circ}$ Brix para sólidos solúveis e $10,53 \%$ para açúcares solúveis totais, observando-se que $77 \%$ do teor de sólidos solúveis são açúcares. Esse valor de sólidos solúveis constatado no presente trabalho é superior ao encontrado na literatura para outras cultivares de mamão. Sólon et al. (2005) verificaram, em mamão Formosa 'Tainung 01', valores de sólidos solúveis que variaram de 11,5 para $10,5 \%$ ao longo de 38 dias de armazenamento, valores inferiores ao constatado no presente trabalho. Os altos teores de sólidos solúveis observados nesse híbrido representam uma grande vantagem para comercialização, já que uma das principais exigências do mercado consumidor é um alto teor dessa característica. A baixa variação nos teores de açúcares e nos sólidos solúveis durante o armazenamento pode ser justificada pelo fato de os teores de amido não terem sido hidrolisados para produção de açúcares solúveis durante o armazenamento, pois Ribeiro (2002) observou que não houve diferença significativa nos teores de amido e sólidos solúveis durante o armazenamento de mamão Formosa 'Tainung' .
A evolução da cor amarela da casca observada ao longo do armazenamento não teve correlação com os teores de sólidos solúveis e açucares totais, que variaram muito pouco após a colheita (quando a casca do fruto apresentava menos de $15 \%$ da cor amarela). Ainda, correlacionando a cor da casca com a firmeza e a acidez, observou-se que ambas as variáveis continuaram decrescendo, mesmo quando a cor da casca já estava completamente amarela.

Houve redução na acidez titulável dos frutos durante o armazenamento (Figura 2B). No dia da colheita, os frutos estavam com $0,214 \%$ de acidez que se reduziu em $38 \%$ no decorrer do período analisado. Essa redução da acidez durante o amadurecimento de frutos deve-se à utilização do ácido na respiração. No caso do mamão, a utilização de ácidos como substrato respiratório é justificado pelo fato de os teores de açúcares, que também são substratos para respiração, reduzirem muito pouco ao longo do armazenamento. Fonseca et al. (2003) verificaram para o mamão 'Golden' maduro valores de acidez semelhante ao constatado no presente trabalho.

A aparência externa e interna dos frutos limitou a sua vida útil pós-colheita em oito dias, ou seja, com notas superiores a 3,0 (Figuras 3Ae 3B). A aparência externa do mamão foi comprometida pelo aparecimento de enrugamento devido à elevada perda de massa, manchas fisiológica, e cicatrizes ocasionadas por danos mecânicos que foram acentuando-se com o armazenamento. Na aparência interna, foi observado amolecimento aquoso da polpa. Não foi observado incidência de fungos ao longo do armazenamento.

Pode-se concluir que o híbrido UENF/Caliman 01 cultivado no Estado do Rio Grande do Norte apresentou uma vida útil póscolheita de oito dias, quando armazenado à temperatura de $25^{\circ} \pm$ $2^{\circ} \mathrm{C}$ e $55 \% \pm 5 \%$ de umidade relativa.
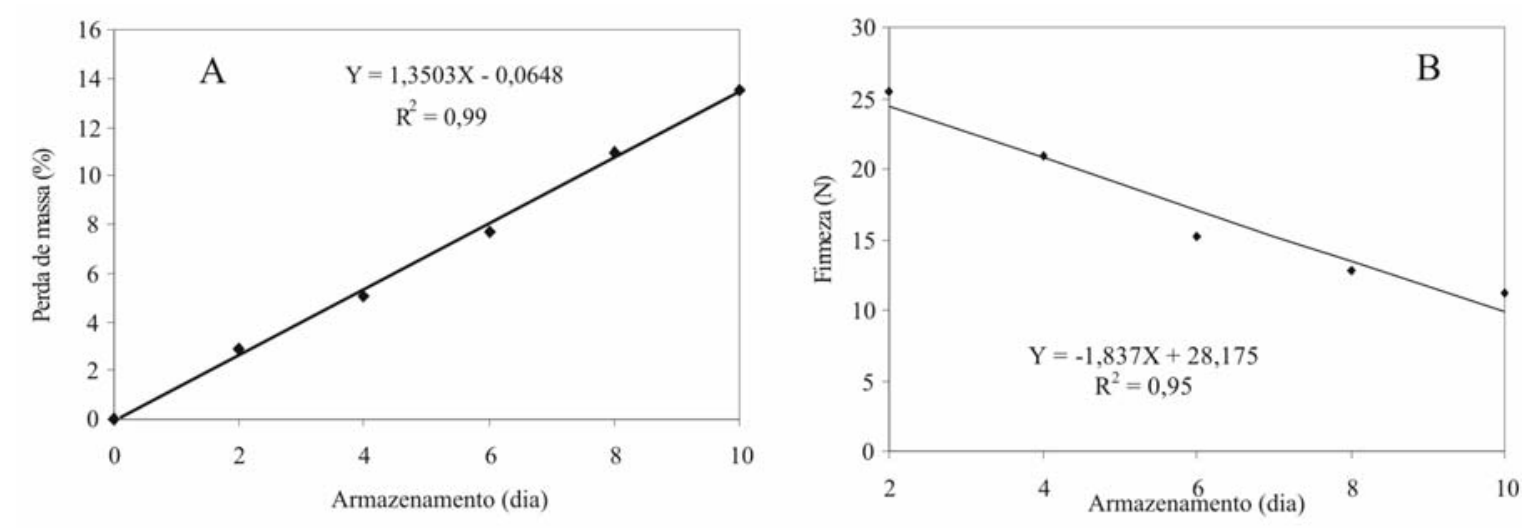

FIGURA 1 - Perda de massa fresca (A) e firmeza da polpa (B) do mamão híbrido UENF/Caliman 01, quando armazenado a $25^{\circ} \pm 2^{\circ} \mathrm{Ce}$ $55 \% \pm 5 \%$ de U.R. 

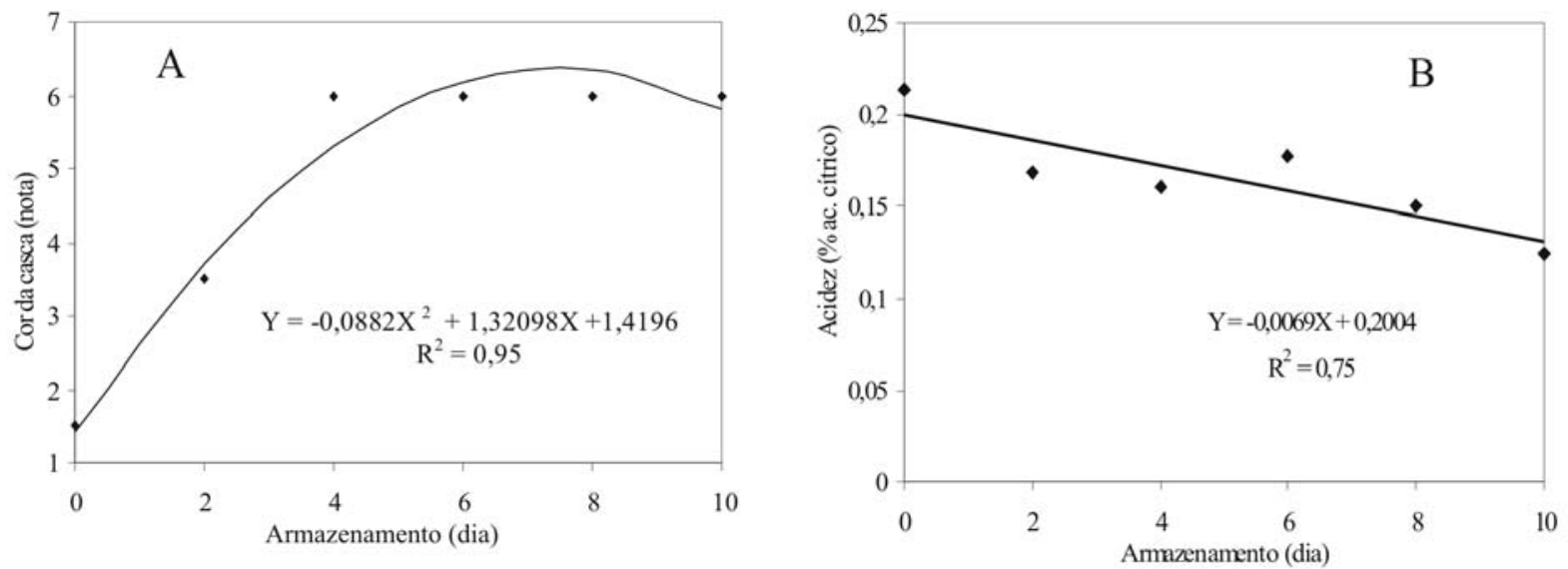

FIGURA 2 - Cor da casca (A) e acidez titulável da polpa (B) do mamão híbrido UENF/Caliman 01, quando armazenado a $25^{\circ} \pm 2^{\circ} \mathrm{Ce} 55 \%$ $\pm 5 \%$ de U.R.
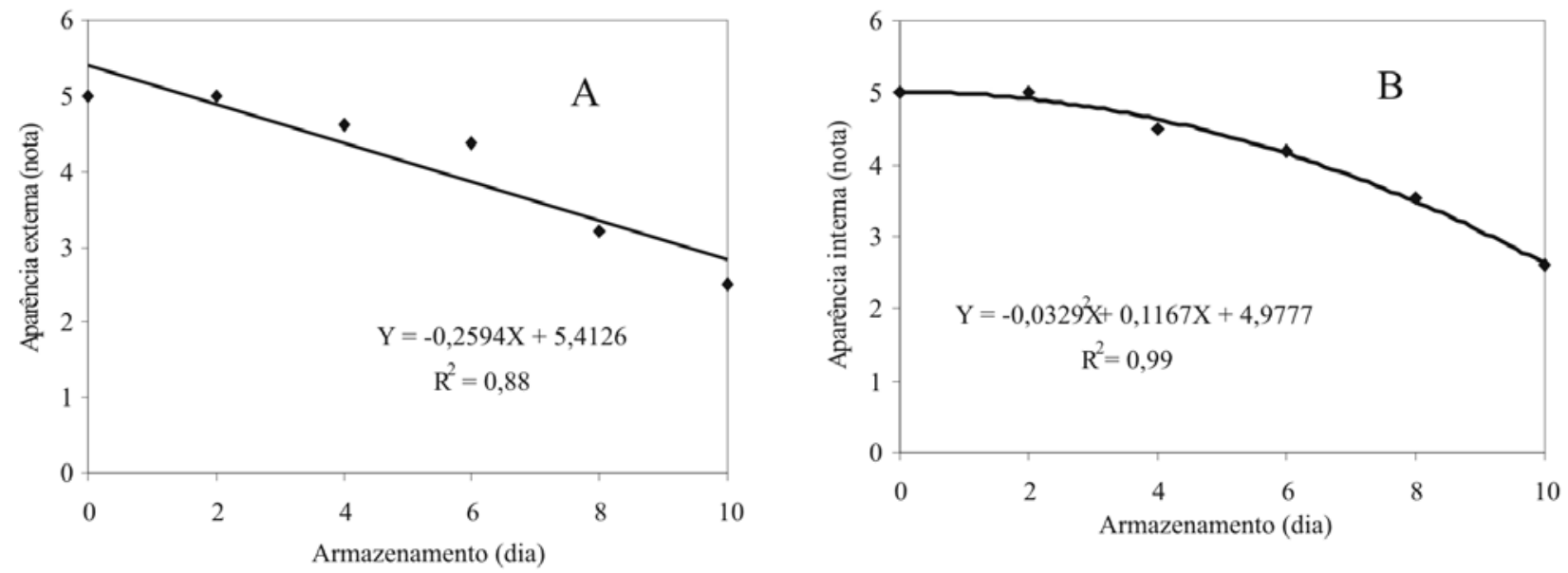

FIGURA 3 - Aparência externa (A) e interna (B) do mamão híbrido UENF/Caliman 01, quando armazenado a $25^{\circ} \pm 2^{\circ} \mathrm{Ce} 55 \% \pm 5 \%$ de U.R. 


\section{REFERÊNCIAS}

AOAC - ASSOCIATION OF OFFICIAL ANALYTICAL CHEMISTRY. Official methods of analysis of the Association of Official Analytical Chemistry. 17 $7^{\text {th }}$ ed. Washington: AOAC, 2002. $1115 \mathrm{p}$.

ASSECOM/RN - ASSOCIAÇÃO DE COMUNICAÇÃO SOCIAL DO ESTADO DO RIO GRANDE DO NORTE. Disponível em: $<$ http://www.assecom.rn.gov.br>. Acesso em: 07 jul. 2006.

AN, J.; PAULL, R. E. Storage temperature and ethylene influence on ripening of papaya fruit. Journal of the American Society for Horticultural Science, Alexandria, v.115, n.6, p.949-953, 1990.

FONSECA, M. J. O. et al. Uso de atmosfera modificada para conservação pós-colheita do mamão "Golden”. Revista Brasileira de Fruticultura, Jaboticabal, v.25, n.3, p.537-539, 2003.

FRUTISÉRIES. Mamão. Brasília: Ministério da Integração Nacional, 2000. 8 p.

INSTITUTO ADOLFO LUTZ. Normas analíticas, métodos químicos e físicos de alimentos. 3.ed. São Paulo: IAL, 1985. v. 1, 553p.

MARIN, A. A. et al. Actividades mono e difenolasa en el extracto crudo del frut chicozapote (Achras sapota). In: FORO INSTITUCIONAL DEL POSGRADO EM ENGENIERIA BIOQUÍMICA, 2001, Mérida. Memórias... Mérida: Instituto Tecnológico de Mérida, 2001.p.22.
OLIVEIRA, M. A. B. de; VIANNI, R.; SOUZA, G. de;ARAÚJO, T. M. de R. Caracterização do estádio de maturação do papaia 'Golden' em função da cor. Revista Brasileira de Fruticultura, Jaboticabal, v.24, n.2, 2002

RIBEIRO, M. D. Estudos preliminares do comportamento do mamão 'Formosa' armazenado em condições ambientais. 2002. 39 f. Monografia (Graduação em Agronomia) - Escola Superior de Agricultura de Mossoró, Mossoró, 2002.

PEREIRA, M. E. C.; SILVA, A. S.; BISPO, A. S. R.; SANTOS, D. B. dos; SANTOS, S. B. dos; SANTOS, V. J. dos. Amadurecimento de mamão formosa com revestimento comestível à base de fécula de mandioca. Ciência Agrotécnica, Lavras, v. 30, n. 6. p. 1116-1119, 2006.

ROCHA, R. H. C. et al. Qualidade pós-colheita do mamão Formosa armazenado sob refrigeração. Revista Brasileira de Fruticultura, Jaboticabal, v.27, n.3, p.386-389, 2005.

SOLON, K. N. et al. Conservação pós-colheita do mamão Formosa produzido no Vale do Assu sob atmosfera modificada. Caatinga, Mossoró. v. 18, n. 2, p. 105 - 111, 2005.

YEMN, E. W.; WILLS, A. J. The estimation of carbohydrate in plant extracts by antrone. The Biochemical Journal, London, $\mathrm{v}$, 57, p. $504-514,1954$. 